\title{
Lengua minor(iz)ada, lengua deseada: sobre las denominaciones identitarias de productos agroalimentarios en lengua occitana ${ }^{1}$
}

\author{
Minorized language, desired language: On the identity \\ denominations of products agro-food in Occitan language \\ Henri Boyer* \\ Université Paul-Valéry Montpellier 3, Laboratoire dipralang (EA 739) \\ ORCID : https://orcid.org/0000-0002-1925-6132
}

ISSN-OI85-4259; e- ISSN: 2007-9I76

Resumen

DOI: http://dx.doi.org/IO.28928/ri/90202I/aotI/boyerh

En esta contribución informamos y cuestionamos las nuevas prácticas escriturales del occitano en los campos del comercio y de la agroalimentación: el lenguaje dominado, minorizado, aparece allí bajo los auspicios de una escenificación de denominaciones de productos de consumo. Estos son usos (muy) minoritarios y relativamente recientes, pero su visibilidad es inversamente proporcional a su normalidad. Lo anterior muestra (pero, ‘̇en qué medida?) un fenómeno ya analizado por otro lado bajo la designación de commodification (mercantilización). $\mathrm{Y}$ a menudo dan testimonio de una creatividad singular. Lo que es paradójico es el surgimiento de tales microactos glotopolíticos (de identidad) relativos a una lengua cuya transmisión se ha interrumpido y cuyos usos sociales "normales" son casi inexistentes. $Y$ esto, en una concurrencia sin precedentes entre la ortografía mistraliana y la escritura clásica de la langue d’oc.

Palabras-clave: lengua minor(iz)ada, patrimonialización, micro-actos glotopolíticos, mercantilización, occitano

\begin{abstract}
In this contribution, we report and question new scriptural practices of Occitan in the fields of trade and agribusiness: the dominated language, minus, appears under the auspices of a staging of denominations of consumer products. These are (very) minority and relatively recent uses, but their visibility is inversely proportional to their normality. They relate (but to what extent?) To a phenomenon analyzed elsewhere under the designation of "commodification". And they often show a singular creativity. What is paradoxical is the emergence of such glottopolitic (identity) micro-acts concerning a language whose transmission has now been interrupted and whose "normal" social uses are almost non-existent. And this, in an unprecedented competition between Mistralian spelling and the classical writing of the langue d'oc.

Key words Language minor(is)ée, identity, patrimonialisation, micro-act glottopolitique, merchandising, Occitan.
\end{abstract}

I Una versión previa de este texto fue presentada en la Conferencia Internacional sobre Problemas y Métodos de Historia de Llengua (Girona, España, $25-28$ de junio de 20I9): «La llengua desitjada» (El idioma deseado). Véase también el reciente simposio internacional: Deseo de idiomas, subjetividad, relación con el conocimiento: ¿son útiles únicamente los idiomas? (I4-15 de febrero de 2019), organizado por el Laboratorio DipRALANG - EA-739 de la Universidad Paul-Valéry Montpellier 3. La asociación de «deseo» $y$ «lenguaje» parece ser recientemente popular.

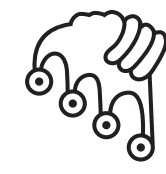

IZTAPALAPA

Agua sobre lajas

* henri.boyer@univ-montp3.fr 


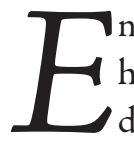

n este texto analizo lo nuevos usos del occitano que pueden observarse desde hace al menos dos décadas en el ámbito del comercio y en particular en el de la alimentación (Alén Garabato, 20I8). Esta emergencia del occitano es, por lo menos, una paradoja etnosociolingüística: una lengua dominada, muy minor(iz)ada, ${ }^{2}$ cuyos usuarios nativos están al borde de la extinción (por no decir que están completamente desaparecidos, si se toma como criterio de apreciación la competencia comunicativa completa), aparece bajo los auspicios de la escenificación de "lexías" y de enunciados en occitano en las designaciones de productos alimentarios (en un sentido amplio). Se trata de usos muy minoritarios, pero en los cuales la visibilidad es inversamente proporcional a su normalidad. Por otro lado, estos usos dan testimonio, a menudo, de una sorprendente creatividad. Así, nombrar una cerveza artesanal "Trobairitz" (trovadora), una cosecha de vino blanco "Rimeta" (rimita, poemita) o un tipo de pastas alimentarias "camba de blat" (pierna/tallo de trigo para las pastas pennes) no es un acto banal. ${ }^{3}$

2 Podemos distinguir, siguiendo a otros autores, en lo que respecta a los efectos destructivos de la dominación lingüística, dos fenómenos:

- La minoración de tipo cualitativo, que lleva a restringir el espacio comunicacional de una lengua hasta el punto de convertirla en una lengua menor, porque ha sido privada de las prerrogativas de un lenguaje de pleno ejercicio social (hasta quedar reservada exclusivamente para el ámbito privado, fase final que anuncia su pura y simple desaparición), proceso que se alimenta de una ideología y por tanto, de representaciones desvalorizantes.

- La minorización, si bien muchas veces es concomitante con la minoración, es mucho más cuantitativa, y concierne a la restricción de usuarios, que puede llegar a una rarefacción de estos mismos usuarios y por lo tanto a una marginación de la lengua dominanda a favor de la lengua dominante. Esto puede ocurrir, en ocasiones, a pesar de cierta visibilidad e incluso vitalidad sociolingüística. Es para dar cuenta de este proceso de enmarañar que utilizo el término "minor(iz)ación" (Boyer, 2017:78).

Las observaciones que se han informado en este estudio se basan en una encuesta documental y en entrevistas semiestructuradas realizadas en 2017-2019 como parte del proyecto de investigación ECO oc del Laboratorio DipRALANG-Université Montpellier 
Sin duda, la enseñanza del occitano prospera en las Calandretas ${ }^{4}$ e incluso en la enseñanza pública francesa (existen programas educativos bilingües). Y con esto no se está diciendo que el fenómeno que se aborda aquí no tenga un vínculo con una evolución positiva de la presencia escolar del occitano. Sin embargo, la aparición de tales prácticas con respecto a una lengua cuya transmisión se ha interrumpido y cuyo uso social actual es casi inexistente es un fenómeno singular. Y más aún, este uso escritural en sí paradójico parece verdaderamente complacerse en la paradoja: se hace uso sin complejo de la escritura clásica del occitano (desde luego sin eliminar completamente la escritura "felibrena", propia de los seguidores de Fréderic Mistral), a menudo explicándose además a través de un discurso epilingüista nostálgico. ${ }^{5}$

Es evidente que no se trata de un fenómeno sociolingüístico aislado geográficamente. Se ha podido observar, por ejemplo, en Costa (2010), en Alén Garabato (2018), también en Robert-Demontrond, Joyau, Bougeard-Delfosse (2010) y en Duchêne y Heller (2012), así como en Fournier, Crozat, Bernie-Boissard, Chastagner (20I2) durante los últimos decenios (todo ello ha sido en diversos contextos de dominación lingüística, e incluso de sustitución avanzada de una lengua minoritaria y fuertemente disminuida) una nueva modalidad de producción de identidad lingüística, nombrada en el campo de mercantilización de habla anglosajona como commodification. En el contexto francófono esto se ha estudiado bajo el nombre de "marchandisation", y consiste en utilizar la lengua-cultura dominada (minoritaria/ disminuida) a través de una patrimonialización discursiva.

Obviamente, el primer cuestionamiento se refiere a las motivaciones de tal práctica: ¿es la búsqueda de un beneficio, de una ganancia, de un valor agregado, desde el punto de vista simbólico, pero también desde el punto de vista comercial (y turístico en algunos casos) que es contemplado, o de los dos en conjunto?, o ¿se trata de una forma más desinteresada, subjetiva y a veces nostálgica, pero no obstante voluntarista, de un acto glotopolítico local? Se entenderá que para mí se trata de un haz de motivaciones que no son totalmente fáciles de dividir.

3 (responsable: Carmen Alén Garabato), cofinanciado por DGLflF (Ministerio de Cultura y Comunicación).

4 Escuelas asociativas en las que se practica una enseñanza inmersiva del occitano y una pedagogía Freinet.

5 Ciertamente hay evidencia del uso escrito del occitano con fines propagandísticos no solo en el momento de la revolución (Boyer, 1985; Garabato, 1999), sino también en los siglos xix y xx (Boyer, 1989). Sin embargo, estos testimonios son de naturaleza sustancialmente diferente. 


\section{Algunas reflexiones preliminares ${ }^{6}$}

Estos requisitos se relacionan, por un lado, con la noción de identidad y la noción asociada de patrimonialización, y por el otro, con la cuestión de la naturaleza, el tamaño y el impacto de una intervención/acción glotopolítica. Especialmente en una situación de conflicto diglósico, es decir, en un contexto de dominio histórico de una lengua dominante ("oficial","nacional") sobre una lengua dominada (minoritaria, "regional") que puede ser también "nacional" o "cooficial").

\section{Sobre la identidad}

Tengo la convicción (a menudo reafirmada y comprobada) de que el imaginario etnosociocultural de grupos y comunidades se desarrolla en un continuo con dos orientaciones: una hacia una regulación ideológica centrípeta, y la otra hacia la producción centrífuga de heterogeneidad y, por lo tanto, de “mestizaje” (Boyer 2008; 2016a).

Considero que reconocer la normalidad de la tensión entre las dos orientaciones de las que acabamos de hablar no significa que olvidemos que "la identidad no es tanto un dato como una esencia", pero que al contrario, se considera que "es el resultado de una producción significativa que la sociedad lingüística permite, rige, controla" (Lafont, 1986: 8) y de la cual el sociolingüista (como el semiólogo o el antropólogo) tiene derecho a informar, si quiere tomar la medida completa de "la fuerza movilizadora excepcional de todo lo que involucra la identidad" (Bourdieu, I980: 69), ya sean microeventos comunicativos, como aquellos que se tratan en esta contribución, o macrofuncionamientos, como hemos visto en otros lugares (Boyer y Cardy, 20II; Fournier et al., 20I2; Boyer, 2008; Boyer, próxima publicación).

Así, mi reflexión se integra a un cuestionamiento más amplio que se refiere a la producción de gestos de identidad en el orden lingüístico, un fenómeno que requiere toda la atención del sociolingüista, en particular porque es indicativo del estado de una comunidad lingüística (Labov, 1976) en términos de su imaginario cultural (en su componente etnosociolingüístico en primer lugar), pasado o presente. Esta reflexión en torno a la identidad depende de una convicción, alimentada por

6 La contribución se reanuda en esta primera parte para reafirmar, en forma sintética, una serie de propuestas que he expuesto en los últimos años en varias publicaciones mencionadas en otras partes del texto. 
observaciones diversificadas a largo plazo: la dinámica de identidad es un motor particularmente poderoso dentro de las sociedades más aparentemente adheridas al mundo posmodernista, tanto en términos de la comunidad nacional en su conjunto como en el de grupos (mujeres, jóvenes, campesinos), áreas (regiones, ciudades) o redes (empresas, asociaciones, clubes deportivos) dentro de la comunidad y, por supuesto, de individuos (véase, por ejemplo, Demontrond, Joyau, Bougeard-Delfosse [2010]; también sobre identidad lingüística, Lagarde [2017], Le Page y Tabouret-Keller [1985], así como Andrée Tabouret-Keller (Varro, 1988: 85), quien señala: "Los elementos lingüísticos no son solo atributos de grupos o comunidades, son en sí mismos los medios por los cuales los individuos dicen su identidad y se identifican con los demás. El lugar existencial del homo, ya sean individuos o grupos, está, por lo tanto, en el lenguaje mismo").

A partir de las dos funciones básicas de cualquier lengua en uso (normal) en una sociedad (Thomas, 1998), podemos ubicar la articulación entre identidad y patrimonialización: se puede considerar que la patrimonialización es un proceso de integración en el conjunto de marcadores de identidad de una sociedad dada, en términos de la comunidad etnosociocultural en su conjunto, o de uno solo de sus componentes (grupo, red), después de la inmovilización, de signos etnosocioculturales que llamo identitemas (Boyer, 20I6b, Boyer, 2017), cuyo contenido simbólico (emblemático/ mítico) es objeto de un consenso casi general.

\section{Los identitemas}

Se trata de unidades de diversa naturaleza lingüística, eventualmente semióticamente compuestas, que muestran un funcionamiento etnosociocultural establecido: un paradigma semiolingüístico ciertamente abierto, pero sobre el cual se ejerce un control ideológico / representacional selectivo y sometido a una presión continua de identidad, generadora de patrimonialización. Si los identitemas muestran como los otros culturemes ${ }^{7}$ una dinámica de simbolización (Boyer, 2008b), previa a la patrimonialización (que necesariamente pasa por una fijación semiótica), en el caso del identitema podemos decir entonces que este proceso de patrimonialización ha logrado una incontestable y estabilizada reputación.

7 Algunos traductores y didácticos (Cuciuc, 20II; Lungu Badea, 2009; Luque Nadal, 2009; Collès, 2007) usan el término cultureme para designar signos etnoculturalesculturales patrimoniales (o aquellos en proceso de ser patrimonializados). 
Se pueden observar dos grandes conjuntos de identitemas (Boyer, 2017), pero el que me interesa aquí es, en una situación de contacto lingüístico (posiblemente con conflicto diglósico), un conjunto de lexías de dimensiones variables prestadas de la lengua menor (dominada) y/o el interlecto presente en la configuración lingüística relativa:

a. cuyo funcionamiento como identitema es establecido (por un periodo indefinido): "septante","votation" en la variente del francés de la Suiza francófona; "péguer" (pegar), "peuchère" (interjección compasiva) en francitán (De Pietro y Matthey, 1993; Boyer, 2010).

b. cuyo funcionamiento como identidad es discontinuo, ocasional y estrechamente dependiente del contexto sociolingüístico y glotopolítico. Se puede tomar como ejemplo el uso exclusivo de uno de los idiomas en concurrencia en un entorno bilingüe/diglósico: este uso reivindica así las dos funciones de este idioma: la función comunicativa y la función identitaria. Es como si en este caso el uso de una palabra en el idioma dominado, amenazado pero reivindicado en concurrencia con una palabra del idioma dominante y amenazante, transformara de facto esta palabra en un identitema.

\section{Política(s) lingüística(s). Acciones/intervenciones glotopolí- ticas}

Con respecto a los niveles de intervención/acción glotopolítica en una sociedad dada, podemos considerar que son (al menos) cuatro en número (que además pueden articularse o al menos funcionar de forma complementaria). Se pueden observar así:

- Políticas lingüísticas globales (nacionales)

- Políticas lingüísticas territoriales (regionales, departamentales, municipales),

- Políticas lingüísticas familiares (dentro de familias bi / plurilingües)

- Políticas lingüísticas locales (dirigidas solo a uno o más segmentos circunscritos de la sociedad: asociaciones (en particular culturales), clubes (por ejemplo, clubes deportivos), grupos (por ejemplo, consumidores), etcétera.

A partir de este último tipo de política lingüística es donde se muestran las prácticas de designación de identidad que aquí se examinan. 


\section{Ideología(s) y contacto(s)/conflicto(s) de lenguas}

Se trata del tercer requisito previo relativo a la interrelación fundamental de representaciones e ideologías en una configuración lingüística dada de tipo conflictivo (diglósico).

Con respecto a las situaciones de dominación lingüística y su resultado, observamos dos polos de resolución del conflicto (de tipo diglósico) (Boyer, 199I):

- Uno es aquel en el que el conflicto ha tenido como fuerza motriz una ideología diglosística hegemónica ( $y$ efectiva) que no ha encontrado una contraideología colectiva y, por lo tanto, una lealtad masiva de los usuarios hacia la lengua menor (y amenazada). La sustitución etnosociolingüística es casi ineludible, aunque puede posponerse por un periodo que puede abarcar varios siglos.

- El otro es aquel en el que una contraideología, que articula representaciones de orden identitario y una actitud de lealtad lingüística (Language Loyalty) (Weinreich, 1970 [1953]: 99-I02) ${ }^{8}$ firme, llega a luchar eficazmente contra la lógica glotofágica del conflicto entre la lengua dominante y la lengua dominada. Esta actitud, que actúa como una interfaz entre las representaciones positivas de una de las lenguas en contacto/conflicto (la que es precisamente dominada, víctima de la competencia desleal, incluso de la imposición) y los comportamientos lingüísticos de los usuarios, es la verdadera fuerza impulsora de la producción de identidad y prácticas colectivas para mantener el uso de la lengua dominada y su transmisión intergeneracional dentro de la familia. La lealtad lingüistica lleva a rechazar y combatir el dominio y la ideología lingüística que lo alimenta, optando por el mantenimiento y el desarrollo de los usos sociales del lenguaje amenazado de sustitución y, por lo tanto, dando la espalda a otras posibles actitudes como el autodesprecio (el "auto-odi" de los sociolingüistas catalanes) y la culpa lingüistica (Lafont, 1971; Boyer, 1997; Alén Garabato y Colonna, 2016) (particularmente pertinente en el primer caso de figura) y, por lo tanto, participando a un proceso de normalización sociolingüística del lenguaje dominado.

8 Weinreich habla en otro texto (en francés) del "sentimiento de fidelidad a la lengua" (Weinreich, 1968). La noción también puede relacionarse con la identidad, el origen étnico (hablamos de lealtad étnica) (Niculescu, 1996). 
- Entre estos dos polos hay muchas variantes en cuanto a la eliminación o presencia (más o menos) efectiva de una actitud de lealtad, especialmente una versión, la que aquí es de interés a nuestro propósito, en la que la valorización reposa (en resumen) no en una representación verdaderamente funcional del lenguaje dominado, sino más bien en una representación ciertamente patrimonial, pero dinámica, de la misma lengua, incluso si fuera menor/disminuida: proveedora de plusvalía identitaria y susceptible de inspirar prácticas de promoción de bienes de consumo (o lugares, objetos, eventos) (véanse, por ejemplo, Ma-Claude, Roy, White, 2006; Alén Garabato 2009; Duchêne y Heller, 20I2; Moses, 20II, Alén Garabato, 20I4; Huck y Kahn, 2009).

Esta valoración de tipo patrimonial puede presentarse en un discurso nostálgico liberado, sin embargo, de una representación de apego al pasado.

\section{Prácticas de nombramiento identitario (comercial) en el área occitano}

La designación de producciones agroalimentarias: hechos y discursos de los actores sociales.

Observamos aquí y allá en el espacio occitano, y en particular en la región Occitania, ${ }^{9}$ el aumento significativo (limitado, ciertamente, pero muy visible) de una explotación de los nombrados estampados occitano/"patois" (el término "patois" todavía se usa con frecuencia como un equivalente de occitano), a veces francitan (Boyer, 2010), para el nombre de productos de naturaleza agroalimentaria principalmente.

Por otra parte, deberíamos señalar una práctica similar, pero más "creativa" en cierto modo, con la aparición de designantes o etiquetas raras o incluso inéditas (aún en occitano, sin embargo) que están así investidas de manera fulgurante con un estatus de identitemas. ${ }^{10}$

9 Véase Alén Garabato, 2018; Boyer, 2019.

${ }^{10}$ Este fenómeno también se refiere, desde hace tiempo, a las designaciones de empresas (principalmente negocios) (véanse Boyer,1984; Alén Garabato, 2007). 


\section{Pastas}

En la empresa agrícola Périès se produce pasta hecha "en la granja" (en la región de Aude) a partir del trigo elaborado en el mismo lugar por la propia empresa, llamando los diversos tipos de pasta con designantes en lengua occitana, en relación con la forma específica del producto. ${ }^{11}$ Es esta empresa la que aparentemente inauguró este enfoque, ${ }^{12}$ pero tomó la decisión de respetar la norma occitana "clásica".

La empresa agrícola Périès ofrece una amplia variedad de pastas, y encontramos los siguientes designantes, escritos en el envase, perfectamente conformes a la apariencia de los diversos tipos de productos que comercializa la empresa: cauquilha 'concha', cresta 'cresta', virona 'zarcillo', dentela 'encaje', escagaròl 'caracol', pichòt 'pequeño?', camba de blat 'pierna/tallo de trigo', brandilha 'ramita'... ${ }^{13}$ Hay una indiscutible riqueza designativa (véase a continuación una muestra de pasta de las fincas de Périès).

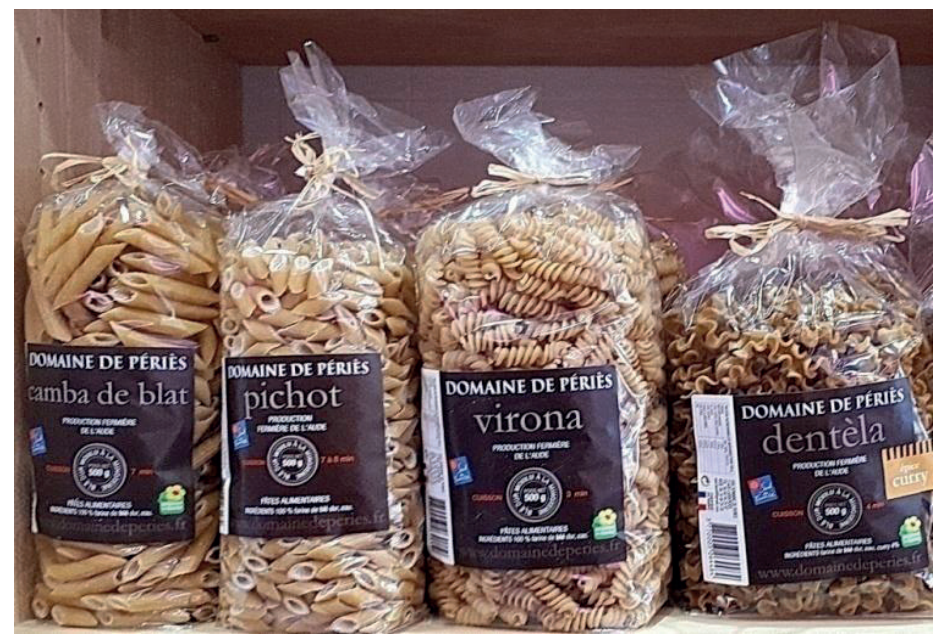

11 Otra marca de pasta, también instalada en Occitania, eligió como denominación: "Ba Pla!" añadiendo la ubicación: "La pasta del Tarn".

12 Según uno de los gerentes de la empresa (entrevista realizada en octubre de 20I7, precisamente "en la granja")

13 Toda la producción se presenta en el sitio web de la compañía: http://www.domainedeperies.fr/ 


\section{Vinos}

Aun con respecto a las nominaciones de producción agroalimentaria, hay entre estas algunas que están relacionadas con una producción históricamente mucho más autóctona: la producción vitivinícola. De hecho, se puede observar un desarrollo que no parece anecdótico de las denominaciones en occitano con respecto a las cosechas de vino del área de Languedoc. ${ }^{14}$

Se trata, en este caso, de explotar los lexemas occitanos, no necesariamente (muy) conocidos por el público en general:

\section{Ejemplos:}

Beluga 'chispa', para una cosecha de vino blanco.

Lou paire el padre', para una cosecha de vino tinto

Alba 'Alba', para una cosecha de vino blanco...

pero también de usar palabras con fuerte carga identitaria (auténticos identitemas para el dominio de oc), como

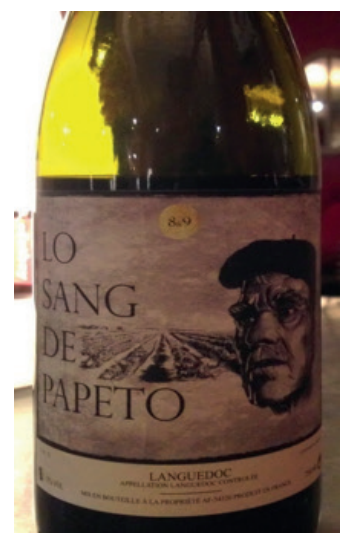

Copa Santa, para una cosecha de vino tinto, en referencia a la famosa canción de Félibres provenzales en homenaje a los catalanes (icuriosamente en ortografía no mistraliana!) Fine amor, para una cosecha de vino tinto, en referencia al Amour Courtois amor cortés'.

También encontramos Lo sang de papeto 'la sangre del abuelo', para una cosecha de vino tinto (es conocido el contenido simbólico del "papet" / "papé" (abuelo) occitano en la celebración nostálgica de las "raíces").

Por último, hay expresiones particularmente notorias, como Qu'es aquo ‘qué es eso?’', para una cosecha de vino tinto, Es d'aqui para una cosecha de vino tinto y una cosecha de vino blanco, o incluso menos conocido: Atal sia 'que así sea', para una cosecha de vino tinto.

${ }^{14}$ Y eso parece ir de la mano con una preocupación bastante reciente por la calidad estética del etiquetado. 


\section{Y cervezas}

Los productores de cerveza artesanal que se establecieron en el último periodo en la misma área geográfica también han tenido el deseo de adoptar nombres arraigados en lo local/regional, más o menos patrimonializados: si Trobairitz'mujer trovadora' es conocido solo por especialistas, Pounchut 'puntiagudo', a menudo utilizado para estigmatizar el acento parisino, A bisto de nas á la vista de la nariz' y en un grado mucho menor: Sabètz que leu (véase más abajo) pueden aún ser parte del panorama lingüístico sonoro de oc, sin que los consumidores tengan una práctica regular de occitano.

Sabètz que leu... La anécdota que condujo a la elección de la denominación es interesante. Se cuenta en el sitio web de la compañía (Aveyron), la Brasserie d'Oltt ${ }^{15}$ "Niños, cuando éramos demasiado bulliciosos, mi abuelo levantaba su boina y decía en voz alta:'Sabètz que lèu!'. En otras palabras: ¡Hay una que se levanta y parece que va a caer! Esta amenaza jamás ejecutada resume el espíritu de esta cerveza artesanal occitana de alto alcohol".

\section{Hipótesis}

No podemos hablar exactamente de resistencia aquí, y mucho menos de reconquista. La sensibilidad al imaginario de las lenguas involucradas (y especialmente la lengua dominada) solicitada no necesariamente conduce a la producción de una contraideología diglósica. Pero podemos hablar, me parece, de microactos glototopolíticos que, a pesar de su carácter etnosociolingüístico reivindicativo a veces asumido, ${ }^{16}$ no corresponden exactamente a acciones de normalización claramente militantes y posiblemente más o menos concertadas, que apuntarían al nivel macroglotopolítico. De ahí que no encajen en la perspectiva de una inversión de sustitución. Sin embargo, una cierta impregnación (bastante relativa pero muy real) de la norma

${ }^{15}$ Es posible consultar el sitio web: brasseriedolt.com/pdf/olt_sabetz.pdf. Uno puede notar en la etiqueta de la cerveza en cuestión la figura mitológica del papé/papet. La misma cervecería nombra a algunas de sus cervezas "Aubrac": este topónimo también es una identitema en uso en Aveyron (se alterna con el uso de logotipos y otras designaciones en occitano, como "Sabètz que leu").

${ }^{16}$ Como aparece en algunas de las entrevistas recopiladas como parte de nuestra encuesta ECO OC. 
escrita occitana "clásica" ${ }^{17}$ parece indicar que la normativización del occitano ya no es exclusiva de la élite occitanista. Como la directora de la empresa de producción de pasta Périès declaró durante la entrevista que nos concedió: "debemos dar nombres occitanos, pero bien escritos; de lo contrario no vale la pena".

Por otro lado, sin embargo, la implementación de una representación patrimonial no necesariamente significa folklorización, en el sentido habitual y más peyorativo del término, incluso si fuera actualizada: me parece innegable que se trata de una auténtica actividad glototopolítica de abajo hacia arriba, ciertamente más simbólica pero seguramente interesada (en particular, pero no solo, desde el punto de vista comercial) que permitiría hablar de mercantilización. Se puede apoyar incluso en redes muy limitadas de defensa y promoción de la lengua dominada, donde sea que existan. No es ajeno a la demanda alterglobal y ecológica de proximidad, de autenticidad. ${ }^{18}$

Por lo tanto, no se trata de revertir la dinámica de un conflicto diglósico multisecular, sino quizás, de cierta manera, de contrarrestar (deliberadamente o no) la ideología diglósica que todavía existe (y seguramente dar la espalda al auto-odio/ auto-denigración) mostrando consideración por el occitano (lo que queda, al menos en el imaginario lingüístico colectivo) y lealtad a las raíces familiares, en primer lugar, y también hacia una identidad lingüística que es en gran parte mitológica pero que parece ser objeto de cierta nostalgia (Boyer 2019). ${ }^{19}$ Se reclama cierta familiaridad

${ }^{17}$ En la historia de la normativización ortográfica de la langue d'oc podemos distinguir la grafía "normalizada", "clásica" (finalizada bajo los auspicios del Institut d'Estudis Occitans y relevantes para todos los dialectos de oc) y la grafía "félibréenne", originalmente formada sobre la base de una de las variantes del dialecto provenzal, adoptada por Frédéric Mistral (Joseph Roumanille fue el principal artesano) y el Félibrige del cual fue el promotor. Se puede decir que la vida de la lengua occitana contemporánea ha sido envenenada por el conflicto entre estas dos grafías, un conflicto que parece estar tendiendo a desaparecer (véase, por ejemplo: Bec, 1963: 97-II5).

18 "Si bien la globalización favorece el consumo de productos de identidad, la creciente demanda de productos locales y regionales está demostrando que el consumidor está apoyando la economía local y regional en la economía global simbolizada por las multinacionales. Consumir local es también reclamar su cultura y la pertenencia a su comunidad" (Robert-Demontrond, Joyau y Bougeard-Delfosse, 2010: 65).

19 ¿Estamos en un "entorno post-diglosico" (Colonna, 2013ः 332 y ss.)? ¿Y son las nuevas operaciones de identidad que observamos "funcionamientos posdiglosicos"? De todos modos, podemos estar de acuerdo con este diagnóstico, que Romain Colonna formula sobre el corso: "es preferible remplazar el concepto de superación del conflicto diglósico por el del desplazamiento" (Colonna, 2013: 332). 
(en gran parte fantaseada) con el "patois". Como lo proclama de manera perentoria, el nombre de esta cosecha de un vino del Languedoc: "Sèm çò que sèm" (véase más abajo). Finalmente, como hemos dicho, hay una novedad: la aparición de un occitano normativizado de acuerdo con la grafía dicha "clásica" ${ }^{20}$ Como si esta irrupción de una identidad escritural occitana en el mercado de la industria alimentaria estuviera acompañada por una dignificación de la lengua de las raíces, llamada cada vez más "occitano" ${ }^{21}$ Y, de hecho, como si el uso de la lengua minor(iz)ada (¿nuevamente "deseada" 22 y legitimada?) fuera digna de una norma gráfica "culta".

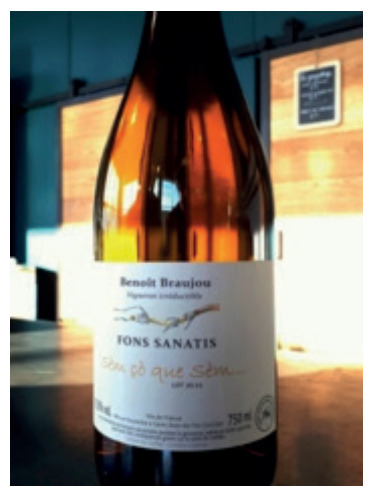

Sèm çò que sèm 'Somos lo que somos'

Algunos extractos de las entrevistas transcritas a continuación permiten ilustrar las hipótesis dadas anteriormente.

La primera entrevista se realizó con Benoit Braujou, "viticultor irreducible” (en la entrevista: вв), que produce, en el viñedo Fons Sanatis, en St Jean de Fos/Aniane (en el departamento de Hérault) una gama de vinos cuyas cosechas se nombran

${ }^{20}$ De ahí la alternancia de diferentes grafías para el mismo morfema (artículo el: lo / lou) o el mismo lexema: el ostal/el oustal [la casa].

${ }^{21}$ Aunque el nombre "occitan(o)" sigue siendo indudablemente minoritario por el momento. También será necesario evaluar en los próximos años el impacto real en el uso del término occitan(o) la elección de "Occitanie" para nombrar la nueva región resultante de la fusión de Midi-Pyrénées y Languedoc-Roussillon (sobre la cuestión del nombre de la lengua occitana y la oposición "occitano"/"patois", véanse, por ejemplo, Gardy, 20oI; Alén Garabato y Boyer, 2004).

${ }^{22}$ Véase el título del xi Colloqui Internacional Problemas y Métodos de Història de la Llengua (Girona, 25-28 de junio de 2019): "La lengua desitjada". 
en occitano: "Sèm çò que sèm" (Somos lo que somos), "Rimeta" (rimita, poemita), "Sirventès" (producción satírica de los trovadores occitanos):

EI -"Sèm çò que sèm" / entonces / nos gustaría preguntarle ¿qué motivó su elección? / antes que nada, ¿es sensible al idioma occitano?

вв -Bueno, no lo usaría si no fuera sensible.

EI -Está bien / ¿lo ha hablado?

вв -Lo hablo muy poco.

EI - ¿Lo ha escuchado?

вв -Sí / lo entiendo / no lo hablo mucho / es / es / porque era el idioma prohibido / y tuve abuelos que eran muy respetuosos / entonces / me hablaban en occitano cuando hacía una travesura / cuando hacíamos cosas que otros no debían escuchar /// así que hablé occitano en el bosque o al borde del agua / los guardias no iban allá / iya ve!

EI $-¡$ ¿Es de aquí?

вв-Sí.

EI -Entonces usted es de...

вв -De Saint-Jean-de-Fos Aniane.

E2 -Pero lo escribe bien de todos modos / lo escribe bien / aparentemente pone acentos.

EI -Así es / cómo lo hizo / porque no todos tienen un buen conocimiento del occitano y su ortografía.

вв - ¡Sólo se necesita leer!

EI -¿Así que estudió?

вв-Sí / y luego, bueno / Tengo amigos que hablan occitano regularmente / Tengo ... leo un poco en occitano / y ya está.

E2 -Y para elaborar las etiquetas / usted llamó à...

$\mathrm{V}-\mathrm{A}$ mí.

E2 -Es usted mismo / es usted / entonces usted hace todo / el vino y el resto.

EI -De hecho en toda su producción / ha elegido nombres occitanos / todos.

вв -Sí / casi / sí / que tienen relación a la historia / con mis raíces.

EI - ¿Tiene que buscar un poco de todos modos?

вв -No necesariamente no.

EI -Le gusta.

вв $-\mathrm{Si}$, eso es. 
Aunque el occitano ya no sea una lengua realmente hablada por el viticultor, queda el placer y también la historia y las "raíces". Al final de cuentas, se trata de una práctica de nominación claramente de orden identitario: Benoit Braujou afirma el orgullo de estar de "aquí".

La segunda entrevista es la de otro joven viticultor, Aymeric Amiel, quien se hizo cargo (y amplió) con su hermano en 2012 la explotación familiar vitícola ancestral. Crearon juntos una cava particular: el Domaine des Amiel y optaron por hacer ta viticultura "biodinámica" que "va más allá de lo bio"...

Fueron, sobre todo, los dos nombres occitanos de cosechas de vinos los que nos llamaron la atención y nos llevaron a pedir una entrevista: Farem Tot Petar 'Lo volaremos todo' y Mounto Daballo 'Sube Baja. Al interrogar al joven viticultor sobre la elección de estas denominaciones, su respuesta comienza con la historia de su (re) apropiación del occitano:

AA: -Entonces a nosotros / a nosotros nos dejó marcados el occitano / cuando éramos niños, bueno este, nuestros, nuestros abuelos / bisabuelos hablaban un poco occitano / vivíamos en una familia / realmente arraigada / no lo hablamos / obviamente / en la escuela / tampoco lo hablamos / yo / lo estudié un poco en sexto / opcional / pero bueno / nada más / eso / y entonces / volvimos a aprender el occitano realmente cuando comenzamos con mi hermano a jugar en la selección occitana de fútbol.

E2:-¿НHay una selección occitana?

AA: -hay una selección occitana de fútbol que existe desde 2004 / y cuya vocación era dar a conocer la lengua y la cultura occitanas a través de este vector universal que es el fútbol / y / o era xxx en ese momento quién se encargaba de eso / con un entrenador que también era cómo decir un literato digamos / de Toulouse / y / yo llegué a esta selección por amigos que jugaban allí y luego de repente nos pusimos realmente a practicar el occitano entre nosotros.

$[\ldots]$

E I: -Bien / y así / es todo a través de esto que / bueno.

AA: -Así que a través de esto / lo practicamos de vez en cuando / siempre hemos usado / expresiones y todo eso / y luego: este: / son unas: son todavía sonoridades que que hablan que son agradables / que atraen la vista o los ojos / la gente no sabe lo que es, de repente esto crea la pregunta / crea la explicación / y a nosotros y a nosotros nos eso pues / no tenemos muchos medios hoy para hacer que el idioma viva la lengua entonces / con nuestras cosechas es / entonces una forma de: despertar un poco de interés de la gente. 
[...]

EI: -Pero: ¿la elección concretamente de / "Farem Tot Petar" y "Mounto Daballo"? AA: -Bueno, siempre hay una explicación / este "Mounto Daballo" / Monte Descend / ¿por qué? / porque decimos que es un vino que baja más rápido de lo que se pone en la boca / es un vino de sed / es un vino fácil / conoces a Lucky Luke / el vaquero que dispara más rápido que su sombra / ese es el vino que se puede beber más rápido que su sombra.

E2: -Es interesante su mezcla eh / si miramos la etiqueta / el vaquero bebió la mitad de las botellas / pero aquí / allá está la sombra que todavía está bebiendo.

AA: -Oh, sí / es cierto / la sombra no consigue alcanzarlo/ siempre hay varios niveles de lectura.

E I $:-\succsim$ Es usted quien crea las etiquetas?

AA:-Sí / bueno, somos nosotros quienes tenemos la idea / hacemos un boceto con nuestras cualidades / que son muy sencillas / y pues tenemos amigos que son diseñadores gráficos en Montpellier / son ellos quienes hicieron el sitio / y y son ellos quienes hacen entonces el trabajo de diseño realmente. EI: -Ok / pero: el nombre / ¡la nominación es de ustedes?

AA: -El nombre / la historia / la idea somos nosotros / pues / mi hermano y yo.

EI: -Es usted / "Farem Tot Petar" / bueno / es un tributo a

AA: - "Farem Tot Petar" / es realmente / fue el grito revolucionario de los eventos vinicultores / así que como es un vino espumoso lo suficientemente brillante y natural con un color que explota / son son cosas que-agradan y luego, cuando lo explicamos enseguida, las personas / las personas se ríen / aprecian / recuerdan es agradable. $[\ldots]$

AA:-Lo que nos hizo sentir frustrados / es / este / no poder escribirlo realmente / en occitano // es decir que nos vimos obligados a escribirlo en félibréen o escritura fonética / porque de lo contrario / no se pronunciaría como debería / aquí / si hubiéramos escrito Mounta davalla / la gente hubiera dicho "mónta dabala" y no hubieran dicho "mõnto dabalo".

$[\ldots]$

AA: -En el comercio / las personas que quieren tener una identidad / LOCAL / bueno, usar occitano / es único / es / es la única forma de destacarse como lo hacen los bretones / como lo hacen los corsos / los vascos / excepto que nosotros hemos / hemos perdido un poco la guerra / tal vez estamos tratando un poco de / hacer de nuevo la última batalla por el honor / pero no tenemos.

EI: - "La última batalla por el honor" / ¿utilizaría esta expresión? 
AA: -Sí, porque para mí la guerra / está perdida / no haremos volver a hablar al 30\% de los occitanos / occitano / ni siquiera sé si hay 0.5 / 0.3 / 0.0I\% de personas en Occitania que hablan occitano / es una pena / en el País Vasco / en Cataluña / en Córcega / está mucho más presente / así es.

[...]

EI: -Usted / ¿usted diría que existe una identidad occitana... / ¿Es eso lo que le motiva?

AA: -Lo que nos falta / es / la práctica del idioma / creo que falta de todas formas agrupar a las personas / así es / tenemos una cultura / tenemos un pasado común / pero no se habla el idioma /// Excepto por las expresiones que solía decir el abuelo / abuela, o decir una grosería de vez en cuando / es difícil sentirse occitano cuando uno no tiene entidad administrativa / cuando uno no tiene un idioma / y / creo que haber perdido el idioma / hace que en la batalla / sea muy difícil mantener la identidad, ¿no? / un pueblo es un lugar / una identidad / una cultura y un idioma / sin idioma es complicado.

$[\ldots]$

Aymeric Amiel tiene un discurso en el que la implicación personal en la elección lingüística y cultural es omnipresente y reivindicada. Sin ser un activista, se dice al final de la entrevista comprometido con "la última batalla por el honor" a favor del occitano cuyo nombre defiende sin reservas, y dice que está "frustrado" por haber tenido que imponerse un sistema fonográfico "para los nombres de sus cosechas", una concesión que parece compensar con un discurso explicativo muy positivo, siempre disponible, sobre la lengua y la cultura de oc. Sus comentarios, apoyados por un posicionamiento glotopolítico muy voluntarista, aunque muy claros sobre el presente y el futuro del occitano, reflejan una reflexión real sobre su gesto comercial y también expresan a su manera una nostalgia por una occitanofonía (prestigiosa) desaparecida, que se ve reforzada por la presencia de algunos signos alentadores (Calandretas en particular), y afirman claramente una identidad occitana (que parece lamentar que no sea más dinámica).

Las dos entrevistas que acabamos de mencionar (y que confirman otras entrevistas recogidas durante la misma encuesta) son testimonios particularmente interesantes que implican incontestablemente una modificación (¡jde naturaleza generacional?) de las representaciones del occitano. Ciertamente, la realidad etnosociolingüística societal no ha cambiado mucho y los actores interesados a veces lo notan con amargura; sin embargo, pareciera que el estereotipo ambivalente (Boyer, 2007) del que fue víctima la lengua occitana y que alimentara el autodesprecio y 
la culpabilización hacia el "patois" se encuentre en retirada y además de que, con la progresión tímida pero evidente del uso del término "occitano", aparecen actitudes (y los discursos epilingüísticos relacionados) que valoran la lengua en peligro (una valoración impregnada de nostalgia ) y la escriben de acuerdo con la norma gráfica "occitanista". Esta nueva situación merece la atención de los sociolingüistas: parece suspender el conflicto diglósico en su progresión hacia la sustitución (o al menos algunos de sus aspectos) al inscribir la "mercantilización" de la lengua dominada, minor(iz)ada (el occitano) en una relativa autonomización y también una legitimación relativa de cara al francés (Lafont, 1984).

\section{Referencias bibliográficas}

Alén Garabato, Carmen

1999 Quand le «patois» était politiquement utile, París, L’Harmattan.

Alén Garabato, Carmen

2007 “Le marché en quête d'identitê: L'évolution des dénominations identitaires des entreprises biterroises", en C. Alén Garabato (ed.), Béziers, ville occitane?, Perpignan, Presses Universitaires de Perpignan, pp. 169-178.

Alén Garabato, Carmen

2014 "Langue, identité, médias : stratégie commerciale d'une entreprise galicienne dans les réseaux sociaux”, en K. Djordjevic-Léonard y E. Yasri-Labrique (dirs.), Médias et plurilinguisme. La diversité à l'épreuve, París, Editions des Archives contemporaines, pp. 243-265.

Alén Garabato, Carmen y Colonna Romain (dirs.) 2016 AUTO-ODI. La "baine de soi" en sociolinguistique, París, L'Harmattan. Alén Garabato, Carmen 2009 Langues minoritaires en quête de dignité, París, L'Harmattan.

Alén Garabato, Carmen y Boyer Henri

2004 "Occitan, patois, provençal... dans l'Enquête 'Famille' de l'insee-INeD (1999): les dénominations de la langue d'oc", Lengas, 56, pp. 30I-318

Alén Garabato, Carmen

2018 «Les langues minoritaires/minorées à la conquête de parts de marchë: questionnement général et premiers résultats du projet ECO-OC», Identités, conflits et interventions glottopolitiques, Limoges, Lambert-Lucas. 
Barthes, Roland

1957 Mythologies, París, Seuil (Collection Points).

Bec, Pierre

1963 La langue occitane, París, PUF.

Bourdieu, Pierre

1980 "Lidentité et la représentation", Actes de la recherche en sciences sociales,

Bourdieu, Pierre 35, pp. 63-72.

1982 Ce que parler veut dire, París, Fayard.

Boyer, Henri

1984 «Introuvable et polémique. L'Occitanie et la dénomination des entreBoyer, Henri prises: une pré-enquête», Amiras/Repères, 7, Edisud, pp. 75-83.

I985 «Argumenter en langue dominée: un programme textuel complexe», Lengas I8, (Actes du colloque «La question linguistique au Sud au moment de la Révolution française», tomo II), pp. 299-3I2.

Boyer, Henri

1989 «Usages propagandistes de l'occitan écrit en contexte urbain (xıxe xxe siècles)», Lengas, 25, 1989, pp. 163-180.

Boyer, Henri

I991 Langues en conflit, París, L’Harmattan.

Boyer, Henri

1997 "Conflit d'usages, conflit d'images" dans H. Boyer (éd.): Plurilinguisme : "Contact" ou "conflit" de langues?, París, L’Harmattan, 1997, pp. 9-36.

Boyer, Henri

2007 «Le stéréotypage ambivalent comme indicateur de conflit diglossique», dans H. Boyer (dir.): Stéréotypage, stéréotypes: fonctionnements ordinaires et mises en scène, T4. Langue(s), Discours, París, L'Harmattan, pp. 39-47

Boyer, Henri

2008 Langue et identité. Sur le nationalisme linguistique, Limoges, Lambert-Lucas, $100 \mathrm{p}$

Boyer, Henri

2010 "Que reste-t-il du francitan?», dans Henri Boyer (dir.), Hybrides linguistiques..., París, L'Harmattan, pp. 235-255.

Boyer, Henri

20I6a «Identité (nationale), nationalisme linguistique et politique linguistique.

Réflexions à partir de quelques situations contemporaines», Les Cabiers 
du GEPE, 8/. Langue(s) et espace; langue(s) et identité, Strasbourg: Presses universitaires de Strasbourg, URL : http://cahiersdugepe.misha. Boyer, Henri

$\mathrm{fr} /$ index.php?id $=2948$

2016b Faits et gestes d'identité en discours, París, L'Harmattan, I20 p

Boyer, Henri

2017 «Les identitèmes: construction patrimoniale et célébration», dans M.

S. Berkaine, C Dahou, A. Kis-Marck, F. Roche dirs., Construction/ déconstruction des identités linguistiques, Saint-Denis, Connaissances et Savoirs.

Boyer, Henri

En proceso «Loccitan et le marché au xxie siècle: une patrimonialisation dynamique ? Pratiques de nomination identitaire (commerciale) en Occitaine », en: M. Puyol (dir), Hommages à Christian Lagarde, Presses Universitaires de Perpignan.

Boyer Henri y Cardy Hélène

201 «Localiser, identifier, valoriser», Les collectivités territoriales en quête d'identité, Mots. Les langages du politique, 97, Lyon, Ens Editions, pp. 5-13

Colles, Luc

2007 "Enseigner la langue-culture et les culturèmes", Québec français, I46, pp. 64-65.

Colonna, Romain 2013 Les paradoxes de la domination linguistique, París, L’Harmattan Cuciuc, Nina

201 «Traduction culturelle : transfert de culturèmes », La Linguistique, 47(2), pp. 137-I50.

De Pietro, Jean-François y Marinette Matthey

1993 "Comme Suisses romands, on emploie déjà tellement de germanismes sans sen rendre compte..., Cabiers de l'Institut de Linguistique de Louvain, 19(3-4), pp. I2I-136.

Duchêne, Alexandre y Monica Heller (eds.)

2012 Language in Late Capitalism: Pride and Profit, Nueva York/Londres, Routledge.

Fournier, Laurent Sébastien, Dominique Crozat, Catherine Bernie-Boissard, Claude Chastagner (dirs.)

2012 Patrimoine et désirs d'identité, París L'Harmattan. 
Gardy, Philippe

2001 «Les noms de l'occitan/nommer l'occitan», en Henri Boyer y Philippe Gardy coords., Dix siècles d'usages et d'images de l'occitan. Des Troubadours à l'Internet, París, L'Harmattan, pp. 43-60.

Labov, William 1976 Sociolinguistique, París, Minuit.

Lafont, Robert

I986 “Contrôle d'identités", en La Production d'identités, Montpellier, Université Paul-Valéry-CNRs, pp. 5-18.

Lafont, Robert

I971 "Un problème de culpabilité sociolinguistique: la diglossie franco-occitane", Langue française, 9 .

Lafont, Robert

I984 «Pour retrousser la diglossie», Lengas, I5, pp 5-36.

Lagarde, Christian

2017 "Quelle identité linguistique à l'heure de la mondialisation ?», en Fabienne Crastes (dir.), L'Étranger: altérité, altération, métissage, Ajaccio, Albiana, pp. 95-I05.

Le PAGE, Robert y Andree Tabouret-Keller

1985 Acts of Identity. Creole-Based Appproaches To Language And Ethnicity, Cambridge, Cambridge University Press,

Lungu-Badea, Georgiana

2009 "Remarques sur le concept de culturème", Translationes 1, Timisoara, Editura Universitatii de Vest, pp. 15-78.

Luque Nadal, Lucía

2009 “Los culturemas: unidades lingüísticas, ideológicas o culturales?", Language Design, II, pp. 93-I20.

Maingueneau, Dominique

2006 "Les énoncés détachés dans la presse écrite. De la surassertion à l'aphorisation", en Bonhomme y Lugrin (eds.), Interdiscours et intertextualité dans les médias, Institut de linguistique de l'Université de Neuchâtel, Pp. I07-I20

Moïse, Claudine

20II "Léconomie mondialisée et le tourisme : un domaine à explorer pour la sociolinguistique francophone?", Mondes du Tourisme [en línea], 4, consulta: 15/10/2018, en http://journals.openedition.org/tourisme/447 ; DoI: $10.4000 /$ tourisme. 447 
Moïse, Claudine; Mireille Maclaughlin, S. Roy y C White.

2006 "Le tourisme patrimonial: la commercialisation de l'identité franco-canadienne et ses enjeux langagiers", Langage et société, II8.

Niculescu, Alexandre

1996 «Loyauté linguistique», en H. Goebl, P. H. Nelde, Z. Stary, W. Wölck (eds.), Linguistique de contact, t. I, Berlín/Nueva York, Walter de Gruyter, pp. 715-720.

Robert-Demontrond, Philippe, Anne Joyau y Christine Bougeard-Delfosse

2010 «La sphère marchande comme outils de résistance à la mondialisation: le cas du marché des colas», Management international, I44, pp. 55-68.

Thomas, Paul-Louis

1998 "Fonction communicative et fonction symbolique de la langue, sur l'exemple du serbo-croate: bosniaque, croate, serbe", Revue des Études Slaves, París, Lxx/I, pp. 27-37.

Varro, Gabrielle

1988 "Compte-rendu de: Robert Le Page et Andrée Tabouret-Keller", Lan-

Weinreich, Uriel gage et Société, 46, pp. 8I-86

1968 «Unilinguisme et multilinguisme», en A. Martinet (dir.), Le Langage, Encyclopédie de la Pleiade, París, Gallimard, pp. 647-684

Weinreich, Uriel

1970 [1953] Languages in Contact. Findings and Problems, La Haya/París, Mouton.

Henri Boyer

Profesor universitario emérito en Sociolinguística en la Universidad Paul-Valéry Montpellier 3, Francia. Posee un doctorado de Estado en Letras y Ciencias Humanas (con especialidad en Lingüística) otorgado por la Universidad de Montpellier, Francia, en 1990, y otro doctorado de Tercer Ciclo en Lingüística, otorgado por la misma universidad en 1976. Asimismo, obtuvo una maestría en Letras Modernas y otra en Lingüística en la misma Universidad, en 1972 y 1971. Es fundador de las colecciones "Sociolinguistique" y "Langue et Parole" en la editorial L'Harmattan. Sus líneas de investigación se definen dentro del campo de la sociolingüística, particularmente las identidades etnosociolingüisticas, las políticas lingüísticas, así 
como los nacionalismos lingüísticos y las representaciones sociolingüísticas. Correo electrónico: henri.boyer@univ-montp3.fr

Citar como: Henri Boyer (202I), "Lengua minor(iz)ada, lengua deseada: sobre las denominaciones identitarias de productos agroalimentarios en lengua occitana", Iztapalapa. Revista de Ciencias Sociales y Humanidades, núm. 90, año 42, enero-junio de 202I, ISSN: 2007-9176; Pp. 155-177. Disponible en $<$ http://revistaiztapalapa.izt.uam.mx/index.php/izt/issue/archive $>$. 